\title{
Design theory: an invitation for a quilt of perspectives
}

\author{
Yoram Reich ${ }^{1}$
}

Published online: 13 December 2017

(c) Springer-Verlag London Ltd., part of Springer Nature 2017

Any discipline that aspires to be scientific embraces the study and development of theory as part of its cornerstone. In different sciences, such as for example in physics, there are competing incommensurable theories. Researchers may belong to one group working on a theory, trying to defend and argue its supremacy, without success; in another discipline, such as material science, researchers succeed in connecting multi-level theories and for this effort, received the Nobel Prize.

With such central role to science and impact on research work, theory becomes a point of debate. Similarly in design, and even more so, since design as a discipline, still questions whether it is a science, a practice, or even an art. Consequently, there is no wonder that if you ask a dozen researchers about their interpretations of the concept 'design theory' you will get several different answers. Ask them subsequently about the potential importance of design theory to design research or to their work and you may get similarly diverse responses.

Research in Engineering Design, as a scientific platform, should provide a space for presenting different perspectives about design theory and conducting fruitful dialogue about it. In order to set the stage, the journal is publishing a paper that builds on a keynote lecture presented at ICED15 and summarizes some key contributions to design theory made by members of the Design Theory SIG of the Design Society (Hatchuel et al. 2017). The reviews of the paper reflected important comments as well as differing perspectives on design theory. While the comments improved the paper, the differing perspectives need an open space for discussion, rather than be left in blind reviews.

This is an open invitation to anybody interested in design theory to write a commentary, a perspective, or a critical review, on the subject. The contribution must be grounded in state-of-the-art work and describe new material; it must

Yoram Reich

yoram@eng.tau.ac.il

1 Tel Aviv University, Tel Aviv, Israel relate to the paper at hand, detailing whether the position, supports, objects, or expands particular ideas in the paper. The length of the commentary should be limited to 1000 words; conciseness is important. The commentary will be reviewed. These contributions will appear on the web once accepted and subsequently published in an issue or in several subsequent issues with a response of the authors of the keynote paper.

This is also a test, although not the first one. A smaller 'prototype' took place in 2010 in the journal through a debate arising from a paper by Frey et al. (2009). George Hazelrigg wrote a letter to the editor and I asked him whether he would like it to be public following a response. He agreed and revised his letter for that format and both his letter (Hazelrigg 2010) and the response (Frey at al. 2010) were published with an editorial (Reich 2010). The point of the discussion was not who is right but the logic and consistency of one's perspective. Since then, papers dealing with topics similar to those raised in this exchange are asked to relate their work to these issues. Such debate and future interpretations help to build up common language and a connected body of knowledge for the community, especially when it is such multi-disciplinary. Other journals, notably the Behavioral and Brain Sciences who started it in 1978, ${ }^{1}$ have been practicing such open commentaries or debates very successfully. Lively engagement by the community in response to this call to participate may open a track in the journal of open scholarly discourse.

\section{References}

Frey DD, Herder PM, Wijnia Y, Subramanian E, Katsikopoulos KV, Clausing DP (2009) An evaluation of the Pugh controlled convergence method. Res Eng Des 20:41-58

Frey D, Herder P, Wijnia Y, Katsikopoulos K, de Neufville R, Oye K, Subrahmanian E, Clausing D (2010) Research in engineering

\footnotetext{
${ }^{1}$ See, http://blog.journals.cambridge.org/2017/09/10/behavioraland-brain-sciences-an-example-of-discursive-peer-review/, accessed 28.10.17.
} 
design: the role of mathematical theory and empirical evidence. Res Eng Des 21(3): 145-151

Hatchuel A, Le Masson P, Reich Y. Subrahmanian E (2017) Design theory: a foundation of a new paradigm for design science and engineering. Res Eng Des. https://doi.org/10.1007/s00163-017-0275-2
Hazelrigg GA (2010) The Pugh Controlled Convergence method: model-based evaluation and implications for design theory. Res Eng Des 21(3):143-144

Reich Y (2010) My method is better!, Editorial. Res Eng Des 21(3):137-142 